\title{
Masalah Perpajakan Dalam Beberapa Prasasti Bali Kuno
}

\section{Nyoman Sunarya}

Keywords: inscription, tax, Ancient Bali

\section{How to Cite:}

Sunarya, I. N. Masalah Perpajakan dalam Beberapa Prasasti Bali Kuno. Berkala Arkeologi, 14(2), 170-172. https:// doi.org/10.30883/jba.v14i2.717

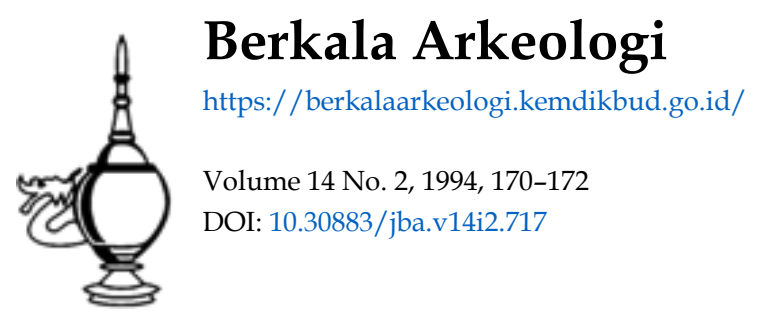

\section{(c) (i) (2)}

This work is licensed under a Creative Commons Attribution-NonCommercial-ShareAlike 4.0 International License. 


\title{
MASALAH PERPAJAKAN DALAM BERAPAPA PRASASTI BALI KUNO
}

\author{
I Nyoman Sunarya \\ (Balai Arkeologi Denpasar)
}

1

Prasastı sebagai tinggalan manusia masa lampau merupakan salah satu data yang dipaka sebagai bahan analisa dalam rangka rekonstruksı kehidupan manusia pendukungnya. Prasasti biasanya ditulis di atas batu, lempengan tembaga atau di atas daun tal (rontal) (Boechari, 1977:1-2) Adapun yang dimuat dalam prasasti menyangkut berbagai aspek kehidupan masyarakat pada saat itu seperti nama raja, unsur penanggalan, struktur pemerintahan, masalah kasta, sistem perpajakan, pola perekonomian, perdagangan, agama; kesenian, dan pertanian (Sukarto,K.Atmojo, 1980 269). Disamping itu prasasti juga memuat luas milayah suatu desa yang dinyatakan berbatasan dengan desa-desa di ke empat penjuru. Di sebelah timur desa $A$, di sebelah selatan desa $B$ dan seterusnya.

Jika diteliti kembali prasasti-prasasti Bali sejak zaman tertua sampai dengan prasasti yang terbit belakangan, menyebutkan beberapa istilah yang berkartan dengan perpajakan. Dalam suatu prasasti di jumpai penyebutan jenis-jenis pajak/ cukai secara rinci dan kadang-kadang berulang dengan beberapa perbedaan kecil. Penyebutan istilah perpajakan dan cukai yang demlkian banyak, menggambarkan seolah-olah kehidupan masyarakat Bali kuno selalu dijejali berbagai jenis pajak dan cukai. Setiap langkah yang dimuatnya selalu diikuti oleh pajak/cukai (Sartono, 1975 203-204).

Berdasarkan data yang tercatat dalam beberapa prasasti Bali kuno, masyarakat Bali kuno pernah mengalami masalah perpajakan seperti tersaji di bawah inı.

\section{II}

Sumber penghasilar kerajaan-kerajaan kuno terdiri atas pajak tanah/hasil bumı, pajak perdagangan/pembelian, pajak usaha dan dendadenda atas segala tindak pidana yang dijatuhkan dalam sidang pengadilan. Semua itu disebut dengan drwyahaji yang secara harfiah berarti milik raja (Boechari, 1981:67). Disamping itu raja juga berhak atas tenaga kerja penduduk untuk mengerjakan keperluannya jika hal itu diperlukan. Di dalam prasasti hal ini ditulis guncanghajibuncanghaji.

Berkaitan dengan kedua jenis pajak ini karama , batwan pada saat pemerintahan raja Anak Wungçumengadu kepada raia, menyampaikan kehendaknya untuk menulis di atas tembaga apa yang menjadi kewajiban (saknaknanya) dan apa yang dibebaskan (sakaluput luputnya). Ini diketahus dari piagam 405 Batunya Ali yang bertarikh 977 c. Pemuka-pemuka Desa Batwan gelisah hatinya karena di dalam piagam yang dihadiahkan oleh raja sebelumnya tidak tercantum masalah perpajakan Dengan perantaraan Rakryan Amali Dyah Bodhisatwa menghadap raja Anak Wungçu kalih bhathari sang lumah ing burwan mwang bhatara dewata sang lumah nng banuwka memohon agar kegelisahannya teratası. Permohonan masyarakat Desa Batwan dikabulkan dengan pemberian piagam dan hendaknya apa yang menjadi ketetapan beliau tidak ada yang mengganggu gugat sampai kelak di kemudian hari lebih-lebih para caksu dan segala jenis pemungut pajak (kala hulahanya hlam dlaha ning ning dlaha, tkapning caksu para caksu mwang sakwehning makilala drbyahaji prokara). Jika ada yang berani melanggar ketetapan ini mereka kena kutuk bhatara Puntahyang.

Masih dalam pemerintahan raja Anak Wungçu, mabwatthaji di Silihan dan Kundungan juga mengalami masalah serupa. Piagamnya dikenal dengan 431 Pengotan A II yang bertarikh 991 C (koleksi Ginarsa, tidak terbit). Orang-orang yang melakukan mahwatthaji di silihan dan Kundungan bingung dan tidak tenang melakukan pekerjaaan karena segala macam kewajibannya kepada nayakanya (sakwen ni drbyahajinya tinahilakna ri na yakanya) tidak dimasukkan pada anugerah raja yang dicandikan dibanu Madatu (ikang tan konggah i pangraksayan yanugrahanira lumahing banu Medatu). Raja akhimya menghadiahkan piagam kepada mabwatthayj di Silihan dan Kundungan serta ketetapan tentarng kewajib yang dibebani. Adapun pajak di Silihan ditetapkan 4 masaka diserahkan kepada sermpun (kunang drwyahayinya i sermpun i Silihan ma 4 kabetian ya) sedangkan drwyahaji di Kundungan 2 ma besamya (drwyahajining Kundungan ma 2 kabehanya).

Prasasti Celepik, Tojan $=439$ Klungkung $A$ (Budiastra,1980:14-17) juga merupakan prasasti raja Anak Wungcu bertarikh 994 Ç dihadiahkan kepada Purusakara di Banu Rara berkenaan dengan kasus perpajakan yang sedang dialami. Disebutkan mereka bersama-sama menghadap paduka Cri Maharaja menuturkan kehendaknya untuk mengerjakan sawah Kadandan yang terletak dikasuwakan Rawas (gumawaiya ikanang sawah 
kadandan i kasuwakan Rawas). Mereka merasa berhak mengerjakan sawah tersebut karena pajak laga pariduh sebesar 1 maça telah dilunasinya. Selain itu telah pula dilakukan pembayaran masing-masing 5 ma kepada kadahulwannya sejak dahulu (kramanya pinalakunya laga pariduh maça 1, kadahulwan manahura sapunwwasantatinya mula ma 5 saputhayu). Dalam pikiran kita timbul pertanyaan apa sebab Purusakara menjadi bingung padahal mereka telah melunasi segala kewajibannya ?. Rupanya Sang admak akmitan yang berdiri dibelakang kasus ini. Sang admak akmitan mengancam akan mengambil sawah garapan Purusakara untuk diberikan kepada penduduk desa lain (ther tan alapana sawah ginawenya, tkapning admak akmitan ngalawak, wwang ring thani salen kunang). Lebih lanjut raja menetapkan tempat pembayaran pajak pada Sang Senapati danda, akmitan danda kunang, sahuwus ming hanyan juga ya anahura). Jika ada orang-orang di Purusakara melakukan tindak kejahatan seperti maling, amumpwanghabet, dro hakanlu, haracun dikenakan denda sesuai dengan ketetapan. Mereka diijinkan menebang kayu-kayu larangan seperti kamiri, bodhi, waring in dan sekar kuning jika tumbuh di sawah dan menaungi lahannya. Penetapan ini disaksikan oleh persidangan lengkap yang dihadiri oleh para Senati, pendeta Siwa dan Budha, dan para Samgat.

Prasasti 556 b. Camlpetan (Poeger,1964 7-21) dikeluarkan pada bulan marggaçira 1071 C oleh raja Jaya Çakti membicarakan keberatan Desa Pengupetan (thani Pengupetan) membayar segala pembeayaan kepada orang-orang Pancanigayan (tan parabya paran denikan karaman Pancanigayan). Untuk menghindari kemungkin. an-kemungkinan kesewenangan orang-orang Pancanigayan dalam kasus ini mereka (penduduk Desa Pengupetan) memohon agar dipisahkan dari Desa Pancanigayan (i kamang thani pengupetan mari sathani pengumpetan mari sathani lawan wwang i pañcanigayan). Permohonan ini dikabulkan oleh raja dengan menetapkan Desa Pangupetan sebagai desa mereka (swatantra $r$ kawakanya) terlepas dari pancanigayan. Orangorang di Pancanigayan tidak berhak lagi memungut pajak terhadapnya

Apa yang terjadi antara Desa Pengupetan mengingatkan kita pada Onghokham yang mengatakan bahwa pada kerajaan-kerajaan tradisional masalah pajak yang terlalu berat dan kesewenangan para pemungut pajak sering dirasakan oleh anggota masyarakat sebagai wajib pajak. Ini mudah dipahami mengingat akibat dari ulah mereka sangat dirasakan oleh masyarakat secara langsung. Mengapa dari catatan-catatan lama yang tampak adalah penyelewengan oleh pejabat rendaha?. Jawabannya adalah dengan menindak pejabat rendahan penguasa tidak menanggung konsekuensi politik (Onghokham, 1985: 115-139).

Prasasti 554 Bwahan C (Poeger, 1964:89. 92) juga atas nama raja Jaya Çakti bertarikh 1068 Ç menyebutkan karaman i wingkang ranu maser kdisan, bwahan dan airawang melalui wakil-wakilnya menghadap raja dengan perantaraan den juru Jayaçakti hendak menyampaikan kesusahannya dan kegelisahan nya (majaraken susahnyangenangenya) berkenaan dengan tidak tertulisnya segala kewajiban mereka terhadap Sang Hyang Silih diri. Tindakan ini semata-mata untuk mengantisipasi tindakan para caksu yang sering menyalahkannya (pinurih purihan dening caksu para caksu. Permasalahan ini diselesaikan dengan penetapan kewajiban kepada Sang Hyang Silih diri berupa saji-saji seperti dahulu setiap bulan asuji seperti bertatah di dalam piagam.

Prasasti 557 Sading B (Poeger, 1964:105109) tarikh 1072 merupakan titah raja Jaya Çakti diturunkan kepada para Senapati, Rakıyan Apatih. Tanda Rakryan berkenaan dengan keadaan desa Bantiran yang ditinggalkan oleh penduduk menuju desa lain (amgil mare Thani salen). Selanjutnya diceritakan penduduk desa ini hanya tersisa satu keluarga yang menunggu desa (kar maçesa sakuren atunggu karaman). Keadaan inilah yang menyebabkan mereka tidak bisa memenuhi kewajibannya membayar pajak pinta panumbas kepada nayakanya (tan kawaça denya ngisyani drwyahaji pinta panumbas ri hayakanya). Untuk menjaga keutuhan dan ketentraman masyarakatnya raja mengeluarkan kebijaksanaan berupa penghapusan beberapa jenis pajak. Selain itu diharapkan pula penduduk bantiran telah berada di desa lain untuk kembali

Pada zaman pemerintahan Çri Maharaja Çri Haji Jaya Pangus sebagian besar desa-desa yang memperoleh piagam atas namanya mengalami masalah yang sama yakni perpajakan. Suatu keistimewaan dari piagam-piagam raja ini adalah dikeluarkan pada hari yang sama (Çaka 1103 Çrawana masa, tithi nawami çukla paksa, pa. wa bu) kecuali prasasti Mantring A

Prasasti 602 Bwahan E (koleksi Ginarsa, tוdak terbit) menuturkan ketidakberdayaan karaman i bwahan wingkang ran u sapanjing thani susah dan bingung karena tersesak hatinya (katidopaya nikang karaman epu kapgan tan wring daya) karena mendapatkan kata sepakat dengan Sang Admak Akmitan Apigajih. Suasana yang demikian menyebabkan penduduk Bwahan gelisah pikirannya dan tidak melakukan pekerjaan dengan tenang di desanya. Mengetahui permasalahan ini raja didampingi kedua permaisurinya mengeluarkan prasasti sebagai pegangan dan penunggu desanya. Kebijaksanaan ini diambil agar segala jenis padrwyahaji tidak terbengkalaı 
(makahetu paryantahsakweh ni padiwyahajyanya). Adapun ketetapan itu berupa pembayaran padrwyahajyan di pakiran-kiran setiap bulan magha çukla). Sang Admak Akmitan Apigajih diharapkan menerima di sana (Sang Admak Akmitan Aprgajih tumarima ya ngkana). Hadir dalam penetapan ini para senati, para samgat dan para pendeta istana

Prasasti 629 Batunya B (Kartika,1987:6083) memberikan data yang serupa tentang pajak. Disebutkan karaman i Batwan tidak berdaya susah serta bingung karena tidak memperoleh kata sepakat dengan para pemungut pajak berkenaan dengan kewajibannya. Masalah ini dapat diatasi dengan terbitnya anugerah raja berupa ketentuan segala jenis pajak yang mesti mereka bayar. Di samping itu agar masalah ini tidak menimbulkan perselisihan yang berlarut-larut antara masyarakat dengan pemungut pajak.

III

Sebagai penutup makalah ini disampaikan bahwa masalah perpajakan bukan hanya mono. polı masyarakat modern, terbukti dari pemberitaan prasasti-prasasti tadi. Setidak-tidaknya dalam kepemimpinan tiga orang raja (Anak Wung२u. Jaya Cakti dan Jaya Pangus) masyarakat Bali kuna mengalami beberapa kali. Dari pemberitaan ini pula diperoleh kesan adanya dua hal yang melatari masalah inı. Pertama para pemungut pajak (Sang Admak Akmiton, Çaksu, Nayaka) dengan jabatannya melakukan tindakan yang meresahkan masyarakat Kedua, masalah inı muncul akibat dari Jumlah mereka yang Jauh berkurang dibandingkan dengan keadaan sebelumnya. Apakah ada motif lain yang melatari masalah-masaIah ını tıdak diketahui dengan pasti.

Tampilnya raja sebagai penengah dalam mengantısipasi permasalahan yang dihadapi masyarakat membuktikan bahwa mereka benar-benar memperhatikan ketentraman dan kesejahteraan rakyatnya. Aturan-aturan yang ditetapkan diharapkan dapat dipakai pedoman dalam mena. nganı masalah serupa

\section{KEPUSTAKAAN}

Boechari, M. . 1977, Epigrafi dan Sejarah Indonesia, Majalah Arkeologi!, Nomor 2, hlm. 1-10

Ulah Para Pomungut Pajak di Dalam Masyarakat Jawa Kuna, Majalah Arkeologi IV, Nomor 1.2, him. 67-87
Budiastra,Putu,1980, Prasasti Banjar Celepik Tojan Klungkung, Museum Bali, Denpasar

Ginarsa, Ktut, tt, Koleksi Naskah Prasasti Bali (tidak terbit).

Onghokham,1985, Tradisı dan Korupsi, dalam Bunga Rampai Korupsi Penyunting Mochtar Lubis dan James C. Scott Lembaga Penelitian, Pendidikan, Penerangan Ekonomi dan Sosial (LP3ES), Jakarta

Poeger, I Nyoman, 1964, Raja Jaya Çakti di Bali Skripsi F. Sastra Udayana, Denpasar.

Kartika,Nengah,1987, Prasasti Batunya darı Ra. ja Jaya Pangus, Skripsl F.Sastra Udayana Denpasar

Sartono Kartodijo, 1975, Jaman Kuna dalam Sejarah Nasional Indonesia II, Bambang Sumadio (ed), Depdikbud, Jakarta.

Soekarto,K.Atmojo,1980, Sruktur Pomerintahan zamen Jaya Çakti, PIA I, hlm. 269-290 Puslit Arkenas, Jakarta 